\section{A new traction method with use of the snare as a "second hand" during endoscopic submucosal dissection}

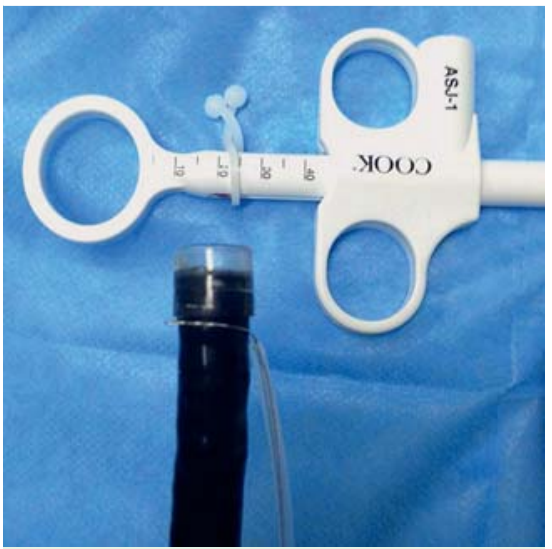

Fig. 1 A snare with a lockable handle is used as a "second hand" during endoscopic submucosal dissection to obtain adequate tissue tension and a clear view of the tissue to be dissected. The snare is tightened at the tip of the endoscope but behind the transparent hood.

Adequate tissue tension and a clear view of the tissue to be dissected are important for effective and safe endoscopic submucosal dissection (ESD). Therefore, various traction methods have been developed to make ESD safer and faster, such as the clip-with-line method [1], magnetic anchor method [2], and double-scope method [3]. Here, a standard snare, often used for polypectomy, serves

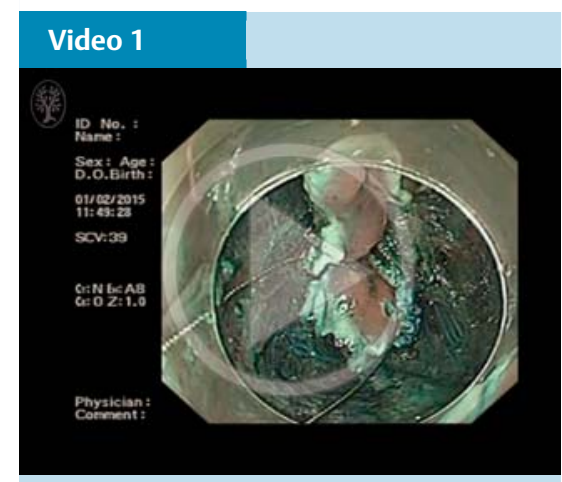

Snare traction-assisted endoscopic submucosal dissection for a fully circumferential lesion at the esophagogastric junction. as a "second hand" (i.e., "traction device") to assist during ESD ( $\bullet$ Video 1). After the creation of a circumferential mucosal incision, adequate submucosal dissection should be done to expose enough tissue to be grasped by the accessory "traction" snare. The endoscope is then removed, and a snare with a lockable handle (ASJ-1; Cook Medical, Bloomington, Indiana, USA) is tightened at the tip of the endoscope but behind the transparent hood ( $\bullet$ Fig. 1). The purpose of this maneuver is to avoid mucosal damage during reinsertion of the scope.

Subsequently, the scope is reinserted along with the snare. After the lesion has been reached, the snare is opened and pushed to be distal to the scope. With a pair of grasping forceps, the snare is anchored around the target lesion and then closed to grasp the lesion ( $\bullet$ Fig. 2 and - Fig.3). The handle of the snare should be locked to enable the endoscopist to control the endoscope and the snare easily and independently.

With gentle traction of the external snare, it is easy to maintain a clear submucosal dissection plane during ESD ( $\bullet$ Fig. 4 and - Video 1). The direction of traction may be controlled not only by pulling but also by pushing. Furthermore, the snare can be released and another part of the lesion grasped as needed. After ESD, the specimen can be retrieved directly with the snare. We have applied this method in a few patients with esophageal, gastric, or rectal lesions. Further studies are planned to prove its feasibility, reproducibility, and efficacy.

Endoscopy_UCTN_Code_TTT_1AO_2AG

Competing interests: None

\section{Peng Jin, Yang Yu, Kuang-I Fu, Dong-} liang Yu, Ai-qin Li, Jian-qiu Sheng

Department of Gastroenterology, Beijing Military General Hospital, Beijing, China

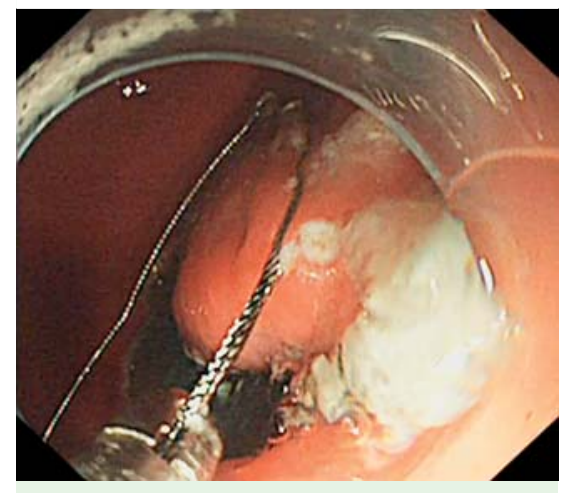

Fig. 2 A pair of grasping forceps is used to anchor the snare around the target lesion after circumferential incision.

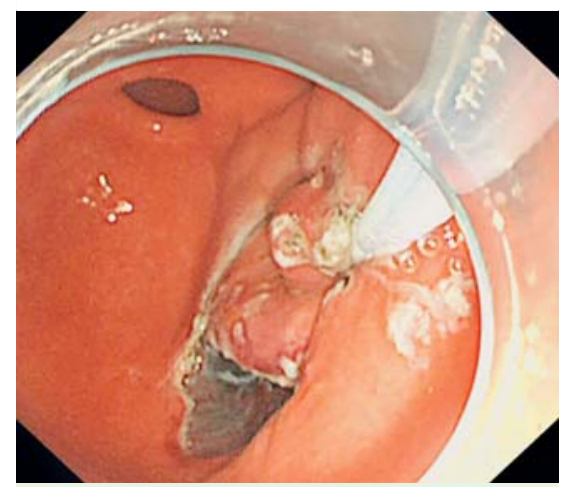

Fig. 3 The snare is closed to grasp the lesion, located at the greater curvature of the antrum.

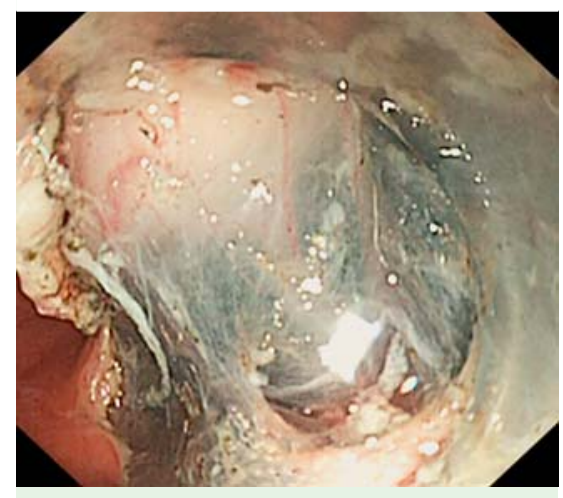

Fig. 4 Moving the scope and pulling the external snare to maintain a clear submucosal dissection plane during endoscopic submucosal dissection.

\section{References}

1 Ota M, Nakamura T, Hayashi K et al. Usefulness of clip traction in the early phase of esophageal endoscopic submucosal dissection. Dig Endosc 2012; 24: 315-318

2 Gotoda T, Oda I, Tamakawa K et al. Prospective clinical trial of magnetic-anchor-guided endoscopic submucosal dissection for large early gastric cancer. Gastrointest Endosc 2009; 69: $10-15$ 
3 Ahn JY, Choi KD, Choi JY et al. Transnasal endoscope-assisted endoscopic submucosal dissection for gastric adenoma and early gastric cancer in the pyloric area: a case series. Endoscopy 2011; 43: 233-235
Bibliography

DOI http://dx.doi.org/

10.1055/s-0034-1392028

Endoscopy 2015; 47: E286-E287

(c) Georg Thieme Verlag KG

Stuttgart · New York

ISSN 0013-726X

\section{Corresponding author \\ Jian-qiu Sheng, MD}

Department of Gastroenterology Beijing Military General Hospital

Nanmencang 5\#

Dongcheng District

Beijing 100700

China

Fax: +86-10-66721299

jianqiu@263.net 